\title{
XIII
}

\section{NOVA LEI DE DROGAS, PANDEMIA E SERVIÇO SOCIAL: DESAFIOS ÉTICO-POLÍTICOS EM CONTEXTO ULTRANEOLIBERAL E AUTORITÁRIO*}

\author{
Cynthia Studart Albuquerque \\ Estenio Ericson Botelho de Azevedo
}

\section{Introdução}

Diferente de outros países latino-americanos, onde os indicadores de violência decaíram com o isolamento social consequente à pandemia de Covid-19, no Brasil, em alguns lugares como no Ceará e no Rio de Janeiro, observou-se o recrudescimento da violência letal. No Ceará, por exemplo, de março a maio, os assassinatos dobraram em comparação com os mesmos meses no ano anterior. "O estado já vinha em uma curva ascendente de homicídios, deflagrada principalmente pelo motim da Polícia Militar ocorrido em fevereiro, mês em que foi registrado um recorde de 459 assassinatos" (BARREIRA; MOURA; LINS; 2020, p.32).

Já no Rio de Janeiro, o aumento da violência foi promovido por incursões beligerantes da polícia nas favelas, tendo como trágico resultado dezenas de homicídios de crianças, jovens, mulheres e homens periféricos que tiveram a vida ceifada por balas perdidas ou direcionadas. Incluem-se aí casos como de Luiz, João, Thiago, Estevão e João Vitor, jovens com infortúnios destinos atravessados por sua condição racial e de classe, assassinados em operações policiais ${ }^{1}$ nas favelas do Rio de Janeiro, que somente em abril mataram $58 \%$ a mais do que em relação ao ano passado.

\footnotetext{
*DOI- 10.29388/978-65-86678-44-4-0-f.337-360

${ }^{1}$ Para mais informações conferir em: <https://brasil.elpais.com/brasil/2020-05-22/um-adolesceste-morto-por-mes-e-o-resultado-das-operacoes-policiais-no-rj.html>.
} 
Evidência disso, foi que a proibição de operações policiais em favelas, durante o Estado de Emergência, pelo Supremo Tribunal Federal (STF), em junho de 2020, significou a queda de $70 \%$ no número de mortes decorrentes destas operações, conforme indicou o estudo Operações policiais e ocorrências criminais: Por um debate público qualificado, do Grupo de Estudos dos Novos Ilegalismos (GENI) da Universidade Federal Fluminense (UFF).

Observamos, também, o rastro de contaminação e mortes por Covid-19 nos sistemas prisional e socioeducativo superlotados pelo grande encarceramento promovido pela política de Guerra às Drogas. Mesmo com a recomendação n. 62, aprovada pelo Conselho Nacional de Justiça (CNJ), em 17 de março, com uma série de orientações para evitar e conter contaminações em massa no sistema prisional e socioeducativo, registra-se uma crescente no número de casos e óbitos.

O Boletim de 09 de setembro de $2020^{2}$, do monitoramento semanal realizado pelo $\mathrm{CNJ}$ dos casos de contágios e mortes por Covid-19 nos sistemas prisional e socioeducativo, entre pessoas privadas de liberdade e servidores, indica que, no sistema prisional já são 30.467 pessoas contaminadas. Destas, 21.949 são pessoas presas e 8.518 são servidores; e ainda, 184 óbitos registrados, sendo 106 de pessoas presas e 78 de servidores. Já no sistema socioeducativo, são 3.607 casos confirmados, dos quais 849 são adolescentes privados de liberdade e 2.758 constituem-se por servidores, sendo 19 óbitos destes últimos.

Esses elevados números de contaminação nos fazem refletir sobre as condições indignas de vida das pessoas privadas de liberdade, que não têm sequer o direito da proteção à vida pelas medidas de distanciamento social, mas também, sobre as precárias condições de trabalho dos servidores destes sistemas, dos quais a taxa de óbitos é bastante significativa. No entanto, como já nos provocou Caetano Veloso na canção Haiti, "[...], mas presos são quase todos pretos. Ou quase pretos, ou quase brancos quase pretos de tão pobres. E pobres são como podres e todos sabem como se tratam os pretos".

Aliais, a pandemia do novo coronavírus expôs deliberadamente o racismo estrutural que conforma as relações sociais e de poder

2 Disponível em: <https://www.cnj.jus.br/wp-content/uploads/2020/09/MonitoramentoSemanal-Covid-19-Info-09.09.20.pdf>. 
na sociedade brasileira. A afirmação de que o contágio por Covid-19 é democrático, pois atinge todas as classes, cores e gênero, apresentase não sem suas contradições. Nem todos tiveram o direito de ficar em casa, ou mesmo, Ihes garantido o acesso aos insumos básicos necessários à prevenção como água, sabão e álcool em gel. As mortes, expressivamente, são determinadas pelos marcadores sociais de classe e raça.

Conforme matéria da $\mathrm{CNN}^{3}$, no pico da epidemia no país, em junho de 2020, nas internações por Covid-19, havia um equilíbrio: negros representavam $49,1 \%$ dos internados, enquanto brancos representam 49\%. Mas na análise das mortes, a desigualdade é assustadora: pretos e pardos representavam $57 \%$ dos mortos pela doença, enquanto brancos são $41 \%$ dos mortos, ou seja, morria neste período, $40 \%$ de pessoas negras a mais do que brancas. Outro elemento, é que os profissionais na linha de frente no enfrentamento da doença, como enfermeiros, técnicos de enfermagem e assistentes sociais, em maioria são pessoas negras. Sem falar nas precárias condições de vida e de trabalho da população negra no país, que repercute em comorbidades e riscos à saúde e no difícil acesso aos serviços de saúde em seus territórios de moradia.

As pessoas negras não são integradas no mercado, seja como cidadão-consumidor, seja como trabalhador-segurado. Desse modo, como sinaliza Almeida (2019, p. 207), o racismo as extermina por "[...] fome, epidemias ou pela eliminação física promovida direta ou indiretamente pelo Estado" e sua necropolítica, de matar e deixar morrer (MBEMBE, 2018). Dito de outro modo, no neoliberalismo há uma política de produção da morte, seja por meio de ações diretas, seja por ausência de ações de manutenção da vida. Não por acaso a maior parte destas vidas assassinadas ou deixadas à morte é composta por pessoas negras.

A pandemia de Covid-19, pois, evidenciou o quão estamos mergulhados no pântano movediço de incertezas e inseguranças produzidas pela mais grave e singular crise capitalista vivenciada no novo século: a crise da crise, melhor dizendo, a crise da resposta político-

\footnotetext{
${ }^{3}$ Conferir em: <https://www.cnnbrasil.com.br/saude/2020/06/05/negros-morrem-40-maisque-brancos-por-coronavirus-no-brasil>.
} 
econômica à crise da regulação social e de acumulação capitalista iniciada ainda no século passado, ou seja, vivemos atualmente uma crise do neoliberalismo.

No caso brasileiro, enfrentamos uma crise que se apresenta com particularidades específicas associadas ao nosso passado colonial e ao processo de constituição do país como nação moderna. Uma modernização conservadora (FERNANDES, 2006) realizada através de "acordos pelo alto" e que teve como pilar estruturante o racismo, conformando uma sofisticada síntese entre questão racial e questão social, em que uma de suas mais violentas expressões, é a "questão das drogas" contemporânea. E como tal, e de modo ainda mais significativo "[...] no contexto da crise, o racismo é um elemento de racionalidade, de normalidade e que se apresenta como modo de integração possível de uma sociedade em que os conflitos tornam-se cada vez mais agudos" (ALMEIDA, 2019, p. 207).

Hoje estamos diante da convergência das crises capitalistas: econômica, sanitária, ambiental e democrática. Uma ambiência que parece conduzir-nos para uma experiência pós-democrática (CASARA, 2017) do Estado brasileiro sob determinação ultraneoliberal, neoconservadora e autoritária, que se instrumentaliza pela reatualização de dispositivos penais como a Nova Lei de Drogas, a Lei de Segurança Nacional e a Lei Anti-crime. Isto tem como resultado a normalização da barbárie, da violência e da morte de determinados indivíduos considerados e produzidos como indesejáveis para o capital, com suas marcas de classe e raça.

Para melhor compreendermos as determinações, contradições e particularidades que produzem a realidade acima descrita, é preciso apreendermos a economia política da guerra às drogas e o seu recrudescimento no contexto pandêmico. Para este fim, o presente capítulo intencionou analisar as mudanças recentes na Política sobre Drogas e suas repercussões para o Serviço Social brasileiro, ou seja, pretende-se depreender os desafios ético-políticos nas respostas da profissão à "questão das drogas" na realidade brasileira, em tempos de Covid-19. Todavia, cabe aqui inicialmente considerarmos o contexto da crise neoliberal brasileira e nela os tensionamentos provocados pela Guerra às Drogas como expressão do controle social da classe trabalhadora e de suas frações racializadas. 


\section{Crítica da economia política da guerra às drogas: crise ca- pitalista, proibicionismo e racismo estrutural brasileiro}

As substâncias psicoativas, hoje classificadas como drogas, desde cedo fizeram parte do rol de mercadorias funcionais à acumulação capitalista. Bem na verdade, pessoas negras e psicoativos, que hoje participam de modo significativo na reprodução capitalista ampliada, foram duas mercadorias centrais na economia colonial e fundamentais para acumulação primitiva de capital, sua consolidação e universalização.

De um lado, a descoberta das plantas mágicas e seus usos pelos novos povos permitiram a incorporação destas substâncias às práticas de consumo da civilização europeia, "[...] tais como o haxixe, o ópio e o tabaco, além de especiarias e novos fármacos" (BOITEUX, 2006, p. 27), ou seja, a produção e a comercialização de substâncias psicoativas tiveram lugar central na formação do capitalismo europeu. De outro lado, importa dizer que o trabalho escravo expropriado teve nisto determinação central. A mercantilização do povo negro como coisa, como propriedade sob domínio total dos senhores brancos, foi fundamental para o processo de acumulação de capitais, ali já iniciado nos processos de colonização. Conforme Marx (2013, p. 821822) destaca:

A descoberta das terras auríferas e argentíferas na América, o extermínio, a escravização e o soterramento da população nativa nas minas, o começo da conquista e saqueio das Índias Orientais, a transformação da África numa reserva para a caça comercial de peles-negras caracterizam a aurora da era da produção capitalista. Esses processos idílicos constituem momentos fundamentais da acumulação primitiva [...] É sabido que a Companhia Inglesa das índias orientais obteve, além do domínio político nas Índias Orientais, o monopólio do comércio de chá, bem como do comércio chinês em geral e do transporte de produtos para a Europa. Mas a navegação costeira na Índia e entre as Ilhas, assim como o comércio no interior da Índia, tornaram-se monopólio dos altos funcionários da Companhia. Os monopólios de sal, ópio, bétel e outras mercadorias eram minas inesgotáveis de riqueza. 
Para o autor citado acima, "a riqueza das sociedades onde reina o modo de produção capitalista aparece como uma grande coleção de mercadorias" (MARX, 2013, p.113). Nesta coleção, estão também presentes as chamadas drogas, isto é, substâncias psicoativas que, historicamente, são utilizadas para diversos fins, mas que na modernidade se transformaram em mercadorias. Ao adquirir esse status, além de já portar valores de uso, pois respondem a determinadas necessidades humanas e se distinguem qualitativamente de outros produtos do trabalho humano, passam também a possuir valores de troca, mediadas pelo quantum de trabalho necessário à sua produção, o que justamente às coloca no mundo das mercadorias, a elas equivalendo-se quantitativamente. Como mercadoria, pois, a droga atende necessidades humanas particulares e necessidades mercantis com foco na valorização do capital.

A mercadoria é, antes de tudo, um objeto externo, uma coisa que, por meio de suas propriedades, satisfaz necessidades humanas de um tipo qualquer. A natureza dessas necessidades - se por exemplo, elas provêm do estômago ou da imaginação - não altera em nada a questão. Tampouco se trata aqui de como a coisa satisfaz a necessidade humana, se diretamente, como meio de subsistência, isto é, como objeto de fruição, ou indiretamente, como meio de produção (MARX, 2013, p. 113).

É, justamente, pela mediação das necessidades sociais em relação às propriedades psicoativas destas substâncias portadoras de utilidade, que se configuram as diversas formas e finalidades históricas para o uso das drogas (BRITES, 2006). As condições postas por esta forma de sociedade fizeram emergir novas necessidades de uso de determinadas substâncias e da relação destas com a classe trabaIhadora.

Valois (2017) informa que Marx viveu num período em que as mães operárias, na Inglaterra, sem ter com quem deixar os filhos para trabalharem nas fábricas, davam ópio às crianças, tal como hoje algumas mães necessitam entorpecer seus filhos de Ritalina. A condição humana de consumidores de drogas foi potencializada na era mercantil e industrial, e hoje determina nossa condição objetiva e subjetiva de existência no mundo. "Drogas para trabalhar, para dor- 
mir, para fazer sexo, para vencer a tristeza, o cansaço, o tédio, o esquecimento, a desmotivação"; drogas como alternativa, ainda que marginal de sobrevivência, por meio das atividades produtivas e de comercialização ilegais. Cada vez mais nossa subjetividade, e a condição objetiva de vida de um segmento da classe que vive do trabalho, é modulada, como requisito determinante, "não só na economia estrito senso das sociedades, mas nas economias psíquicas" (CARNEIRO, 2019, p. 10).

Nessa direção, o consumo das drogas não está desvinculado ao hiperconsumo das mercadorias em geral, de uma mercantilização universal de todas as coisas em um sistema que prevalece a lógica das necessidades do capital sobre as necessidades das pessoas. "Há um entrelaçamento entre as necessidades de expansão do capital e a reprodução das necessidades de consumo, dentre essas, o consumo de drogas" (SANTOS; SOARES, 2013, p. 43-47).

\begin{abstract}
A forma-mercadoria das substâncias psicoativas está indissociavelmente relacionada com o trabalho alienado no capital, ou seja, é produzido nos mesmos moldes de produção dos demais produtos, nesse modo de produção que torna o próprio trabalho uma mercadoria. As relações mercantilizadas enquanto formas de regularização capitalista se naturalizam no processo da vida social e dificultam a percepção da relação fetichizada com os produtos do processo de produção. Também a satisfação de necessidades pelas substâncias psicoativas aparece para o consumidor como uma experiência puramente corporal de modificação de sensações e formas de percepção de sua condição física e psíquica, como sendo um tipo de relação natural e não uma construção social reforçando o efeito fetiche e a alienação (Idem, 2013, p. 45).
\end{abstract}

Diga-se ainda, que na forma social capitalista, cuja lógica se volta para o lucro, a droga se insere num processo de produção para a troca: produz-se esta mercadoria não apenas com vistas ao seu uso particular, ou seja, diretamente ligada ao seu consumo imediato, mas para que ela seja trocada, para que ela se insira na grande vitrine mercantil, ainda que por vezes pareça estar num lugar oculto nesta vitrine. Isto porque algumas destas substâncias foram proibidas e tornadas ilegais, passando a ser entendidas como um "problema social", alvo de medidas de controle social punitivo pelo Estado. 
As drogas convertem-se em um problema para a sociedade passando a reclamar respostas estatais no âmbito da repressão, do controle e, posteriormente do cuidado, no contexto da sociedade moderno-capitalista, precisamente, na sua fase monopólica quando as substâncias psicoativas se tornam mercadorias. Paralelamente, no plano ideológico, foi se consolidando uma moldura burguesa fundada numa moralidade voltada para o trabalho e para o controle dos corpos dos trabalhadores, possibilitando a consolidação do proibicionismo. Essa ideologia é alicerçada no estatuto médico-jurídico que oferece um tipo de saber-poder e ganha materialidade através de mecanismos legais e institucionais de controle que estabelecem o fluxo das drogas no livre mercado por meio da dualidade lícitas e ilícitas.

Em síntese,

[...] as substâncias psicoativas tornaram-se mercadorias e passaram a movimentar gigantesco contingente de capital que envolve estruturas produtivas legais, como os grandes laboratórios farmacêuticos e suas cadeias de distribuição e de pesquisa, mas também um conjunto produtivo clandestino que se sustenta no tráfico em níveis diversos e conta com uma rede de apoio que articula grupos criminosos a cartéis políticos em vários âmbitos das estruturas de poder (ALBUQUERQUE; AZEVEDO; NOBRE, 2016, p. 36-37).

Através da ideologia proibicionista ${ }^{4}$, que visa exterminar o uso de algumas substâncias, controlar a circulação e acabar com a produção de certos tipos de drogas, sob direção hegemônica dos Estados Unidos da América (EUA) e da Organização das Nações Unidas (ONU), são criadas legislações de regulamentação, proibição e criminalização da produção, do comércio e do consumo de algumas das substâncias que são tornadas ilícitas.

\footnotetext{
${ }^{4}$ O proibicionismo é, de fato, objetivado através das três convenções da ONU sobre a matéria: a Convenção Única sobre entorpecentes de 1961; o Convênio sobre substâncias psicotrópicas de 1971; e a Convenção de Viena de 1988, realizada contra o tráfico ilícito de entorpecentes e substâncias psicotrópicas. Todavia, embora o Brasil apresente uma relação heterônoma aos EUA, a proibição das drogas no país apresenta particularidades decorrentes do seu passado colonial e da modernização conservadora, principalmente, no período da ditadura civil-militar que, por meio da ideologia da Segurança Nacional, conformou uma perspectiva beligerante do direito penal do inimigo na política sobre drogas.
} 
Neste sentido, a "questão das drogas" torna-se um fenômeno mundial, mais precisamente, no final do século $X X$, quando o mercado das drogas atinge gigantescas proporções sob o julgo da política de Guerra às Drogas. Quando nos referimos à "questão das drogas" mundial, estamos falando de uma expressão da "questão social" na contemporaneidade, delineada a partir das relações entre a produção mercantil das drogas, o proibicionismo e as mudanças no padrão de acumulação capitalista provocadas pela crise estrutural do sistema, a partir dos anos 1970. A "questão das drogas" manifesta uma profunda contradição resultante deste mercado altamente lucrativo composto por drogas legais e ilegais: a criminalização e o extermínio de segmentos pauperizados e racializados da classe trabalhadora; e uma intensa patologização moralizadora fortalecendo o complexo médico-industrial, setor estratégico para acumulação capitalista como uma das respostas à crise da era neoliberal.

Já economia política da guerra às drogas, hoje, também fundamental no processo de reprodução ampliada, abrange desde a produção das drogas-mercadorias por meio do trabalho produtivo explorado, desregulamentado, ilegal e precarizado, do plantio à produção industrial; a distribuição destas mercadorias no mercado ilegal envolvendo trabalho improdutivo, também, fundamental para realização do valor como a atividade de transporte; uma estrutura comercial ilegal e hierarquizada, em seus níveis de comercialização no atacado e no varejo, composta por inúmeros postos de trabalho, também, desregulamentado e precarizado; e o nicho da financeirização responsável por "lavar" as volumosas cifras acumuladas e inseri-las no circuito "legal" de reprodução de capitais.

Nesse horizonte, a nossa análise da "questão das drogas" considera as relações entre pauperização e criminalidade, já que "a atividade econômica ligada ao tráfico de drogas se alimenta da pobreza e da exclusão social" (BOITEUX, 2015, p. 148). Desemprego, miséria, marginalização, fetiche, (in)visibilidade perversa, precarização do trabalho, genocídio da população negra e tantos outros fenômenos que não são, se não, resultado de um enorme contingente populacional que vive à margem da produção e do usufruto da riqueza social e que encontra no consumo e/ou no comércio de drogas a mediação possível para realização das suas necessidades. 
Mais uma vez, aqui aparece aquela relação particular da "questão das drogas" com a questão étnico-racial. Se outrora a população negra usada como instrumento-propriedade foi decisiva no processo inicial de desenvolvimento capitalista, inclusive, participando da produção de determinadas substâncias psicoativas; no contexto contemporâneo, a população negra é a maioria atingida, e com maior concentração, pelos fenômenos citados acima. "A escravidão se esboroou, mas o substituto e o sucessor do escravo não foi o trabalhador negro livre, mas o trabalhador branco livre estrangeiro ou então o homem pobre livre, mestiço ou branco, porém sempre marginalizado sob o regime de produção escravista" (FERNANDES, 2017, p. 38).

Ao conjunto destes trabalhadores negros destituídos das possibilidades de inserção no mercado de trabalho regulado, é imposta sua condução para postos de trabalho periféricos, por meio da disciplina do trabalho dessocializado (WACQUANT, 2007). Ora, diante do desemprego generalizado que atinge, principalmente as frações racializadas do proletariado, o mercado das drogas é uma das atividades econômicas deste mercado periférico, que aparece como modo de sobrevivência que se mantêm e se amplia, à medida que reproduz a mesma lógica, a produção mercantil capitalista e o processo contínuo de valorização do valor .

Nessa perspectiva, a criminalidade não é uma qualidade ontológica de determinados indivíduos, é, antes de tudo, um status atribuído a partir de uma dupla seleção: primeiramente ocorre a seleção dos bens protegidos penalmente e dos comportamentos ofensivos a estes bens; depois sucede a seleção dos indivíduos estigmatizados para responder penalmente as infrações às normas pré-estabelecidas. Assim, a criminalidade é "[...] um bem negativo, distribuído desigualmente conforme a hierarquia dos interesses fixada no sistema socioeconômico e conforme a desigualdade social entre os indivíduos" (BARATTA, 2013, p. 161).

Batista (2003), em sua pesquisa, ao analisar os dados do sistema de justiça criminal brasileiro percebeu a diferenciação existente na aplicação do estereótipo criminal. Aos jovens de classe média, geralmente, Ihes é atribuído o estereótipo médico de consumidor- 
doente; e aos jovens pobres e negros Ihes é atribuído o estereótipo de traficante-delinquente. A autora trabalha com a hipótese de que,

[...] na transição do autoritarismo, da ditadura para a abertura democrática (1978-1988), houve uma transferência do inimigo interno do terrorista para o traficante. Todo o sistema de controle social (incluindo aí suas instituições ideológicas, como os meios de comunicação de massa) convergiu para a confecção do novo estereótipo. $\mathrm{O}$ inimigo, antes circunscrito a um pequeno grupo, se multiplicou nos bairros pobres, na figura do jovem traficante (BATISTA, 2003, p. 40).

Esses elementos visibilizam como o racismo à brasileira é um sofisticado mecanismo de estruturação e reprodução das desigualdades sociorraciais,

[...] mais do que um discurso, o racismo estrutural se materializa não somente pela estigmatização e discriminação racial sofrida pelos negros, mas efetivamente, por meio de medidas de impedimento do acesso aos direitos civis e sociais tais como o voto, a liberdade religiosa, o emprego, a educação, a cultura, a saúde, dentre outros. Ao lado da marginalização imposta, a face mais perversa do racismo estrutural é a histórica criminalização da cultura, da resistência e da existência da população negra. Isto posto, um dos principais dispositivos de criminalização dos negros no país é a Lei de Drogas (ALBUQUERQUE; CARVALHO, 2019, p. 93-94).

Nesse sentido, problematizar a participação do Serviço Social na atual Política sobre Drogas e a reprodução do seu substrato proibicionista no exercício profissional de assistentes sociais, requer a articulação de uma análise mais geral acerca da funcionalidade desta política no contexto de crise neoliberal e do autoritaritarismo de Estado, considerando a particularidade de sua configuração no plano nacional.

\section{Nova Lei de drogas e dispositivos de controle social puniti- vo contemporâneos: desafios éticos políticos contemporâ- neos para o Serviço Social}

Não restam dúvidas de que, na contramão do impávido colosso da chamada Guerra às Drogas, as estatísticas apontam para um 
crescimento sistemático do uso de substâncias psicoativas, sejam elas lícitas ou ilícitas. No caso destas últimas, segundo pesquisa realizada pelo Escritório das Nações Unidas sobre Drogas e Crime (UNODC), ${ }^{5}$ o número de usuários comuns, entre 15 e 64 anos, subiu de 210 milhões em 2009, para 269 milhões em 2018. Quanto aos usuários que fazem uso problemático destas substâncias, o aumento foi de 26 milhões em 2006 para 35,6 milhões em 2018.

Esses dados, por si só, demonstram no mínimo a falibilidade da política de cunho proibicionista. Além disso, esta realidade deve nos chamar atenção para uma leitura mais cuidadosa sobre a ideologia proibicionista e seus dispositivos, dentre eles a Lei 13.840/2019 (Lei de Drogas), buscando compreender o que de fato está em sua base e o que em realidade consiste no seu objetivo e funcionalidade.

A Política sobre Drogas exprime um momento da síntese punição e estrutura social da sociedade burguesa (RUSCH; KIRCHHEIMER, 2004), e por isso ela aparece formatada como tal, justamente, num período determinado de desenvolvimento e organização do modo de produção capitalista, mais precisamente em sua fase neoliberal. Aqui ela se constitui por meio da unidade contraditória entre as políticas sociais e as políticas criminais objetivadas através de dois mecanismos: criminalização e encarceramento para frações mais dessocializadas dos trabalhadores; e abstinência e controle dos corpos para os setores socializáveis.

Neste mesmo horizonte, Wacquant (2007, p. 20) apresenta três estratégias que nas sociedades contemporâneas se conduzem por uma perspectiva que intenta "tratar as condições e as condutas que julgam indesejáveis, ofensivas ou ameaçadoras". Essas estratégias, em níveis aparentemente distintos, são expressões de um mesmo processo que ganha maior corpo no período marcado pela chamada hegemonia "neoliberal". A primeira estratégia é a socialização. Por esta estratégia se busca "agir no nível das estruturas e dos mecanismos coletivos que as produzem e as reproduzem". Já a segunda estratégia, aqui entendida pelo referido autor como medicalização, consiste em "procurar um tratamento médico a um problema, apressadamente definido como uma patologia individual, que deve ser tra-

\footnotetext{
${ }^{5}$ Para mais informações, buscar em: <https://www.unodc.org/lpo-brazil/pt/drogas/index.html>.
} 
tado por profissionais da saúde" (Idem, p. 21). Wacquant (Ibidem) conclui referindo-se à terceira estratégia, que, para ele, é precisamente a penalização. Em suas palavras:

\begin{abstract}
A penalização serve aqui como uma técnica para invisibilização dos 'problemas' sociais que o Estado, enquanto alavanca burocrática da vontade coletiva, não pode ou não se preocupa mais em tratar de forma profunda, e a prisão serve de lata de lixo judiciária em que são lançados os dejetos humanos da sociedade de mercado.
\end{abstract}

É por este prisma que podemos identificar, de forma similar, na Política sobre Drogas brasileira, que até 2019, se estruturava, programaticamente, através da articulação de três instrumentos normativos, quais sejam:

\begin{abstract}
A Política do Ministério da Saúde para Atenção Integral aos usuários de álcool e outras drogas (Brasil, 2004); a Política de Drogas da Secretaria Nacional de Políticas sobre Drogas, vinculada ao Ministério da Justiça (Senad, 2005) e a Lei Federal 11.343, de 2006, que cria o Sistema Nacional de Políticas Públicas sobre Drogas (Sisnad) e normatiza procedimentos de prevenção, reinserção, repressão e define crimes (BRITES, 2015, p. 124-125).
\end{abstract}

Esses três instrumentos balizavam os marcos políticos e legais das respostas sobre drogas no país. Havia um consenso em reconhecer "que o uso de drogas é socialmente determinado, na valorização da abordagem interdisciplinar, na incorporação da perspectiva de redução de danos, no respeito aos direitos humanos e na defesa do direito à saúde" (BRITES, 2015, p. 125). Mesmo assim, nesta conformação da Política de Drogas brasileira, havia "a convivência contraditória e velada entre duas perspectivas antagônicas: a da saúde coletiva e a proibicionista"; uma coexistência inconciliável diante das concepções de indivíduo e sociedade que lhes davam sustentação e, consequentemente, sobre a direção ético-política das respostas produzidas pelo Estado ao consumo de psicoativos.

Essa contradição na Política sobre Drogas é manifestação da dualidade entre assistência e repressão (LIMA, 2009) que acompanha a história das políticas sociais brasileiras. Está vinculada à própria natureza do Estado e do Direito na sociedade capitalista, à formação so- 
cial do Brasil e sua herança conservadora e ao racismo estrutural e suas manifestações de violência, tutela e favor, aspectos que dão forma aos mecanismos de controle e regulação social.

O período dos chamados governos democrático-populares (2002-2010/Lula; 2011-2016/Dilma), é marcado por um significativo avanço nas políticas sociais e de direitos humanos, no emprego e na renda com valorização do salário mínimo e políticas de transferência de renda, repercutindo na redução do índice de desigualdade social. Todavia, transcorreu, também, o maior encarceramento de negros e pobres como nunca visto antes na história desse país. Em doze anos, o crescimento da população carcerária foi de mais de $620 \%$, enquanto o da população brasileira foi em torno de $30 \%$. Vejamos:

Em números absolutos, e considerando o período de 2000 a 2012, percebe-se que, depois de um período de estabilidade no início dos anos 2000 , em que a população carcerária girava em torno dos 230 mil presos, e com a exceção do ano de 2005 , o crescimento foi significativo e constante, de em torno de $8 \%$ ao ano, chegando a um total de 574 mil presos em junho de 2013 (AZEVEDO; CIFALI, 2015, p. 113).

Há que se refletir que os próprios governos petistas construíram os mecanismos e o contexto para esse grande encarceramento, através do fortalecimento dos dispositivos penais e da política de conciliação entre frações de classes com interesses inconciliáveis. Inclusive, através da promulgação da Lei Antiterrorismo produziu-se a possibilidade de criminalização da resistência e da luta política por meio de práticas de governo ao modo do estado de exceção ${ }^{6}$.

Contudo, o golpe de 2016, por meio do impeachment da presidenta Dilma, constituiu-se um marco para reorganização do Estado brasileiro e de suas políticas públicas diante da alteração da correlação de forças na sociedade em que se apresentam fortalecidas as posturas e práticas reacionárias e conservadoras. A realidade contemporânea no país é síntese de crises capitalistas, estruturais e conjunturais, que desembocaram na (im)previsível eleição de Jair Bolsonaro. Mais do que um acidente histórico, esse processo foi "interpela-

\footnotetext{
${ }^{6}$ Talvez a reflexão de Karam (1996) sobre a esquerda punitiva nos ajude a entender as posi ções conservadoras sobre drogas no campo da esquerda - que é amplo e diverso - baseadas nas demandas e na reação punitiva da sociedade.
} 
do por forças econômicas, políticas e sociais mais amplas e poderosas a nível mundial" (VASCONCELOS, 2020, p. 09), que tem como uma das estratégias centrais a produção do inimigo e do ódio como política, objetivando a normalização da violência e da utilização dos mecanismos de controle e punição, tal como a Lei de Drogas.

A marca do (des)governo Bolsonaro é de uma grande ofensiva aos trabalhadores por meio de uma política de ajuste fiscal radicalizada em favor dos "donos do poder"; o desfinanciamento das políticas sociais; processos de mercantilização dos direitos e bens sociais e ambientais; contrarreformas que desmontam a estrutura e organização do Estado e das classes no país como as reformas trabalhistas, da previdência social, administrativa e tributária, que agudizam o desemprego estrutural e a precarização da vida; além da ascensão do conservadorismo, do irracionalismo e do autoritarismo, que confrontam às liberdades democráticas e o pensamento crítico-científico. Essa conjuntura implicou, também, na refuncionalização e/ou reatualização conservadora de dispositivos penais, como a Lei de Segurança Nacional, a Lei Anti-Crime e a Nova Lei de Drogas alinhadas a uma permanente prática de governo pela lógica da exceção, com forte semelhança com a política de Zero Tolerance norte-americana (AGAMBEN, 2004).

A alteração da Lei $11.343 / 2006$ pela Lei $13.840 / 2019$, que estrutura o Sistema Nacional de Políticas sobre Drogas (SISNAD) no país, expressa como aspectos centrais: ações penais mais rígidas contra o tráfico de drogas, substituição da redução de danos como política de cuidado pela abstinência, previsão da internação involuntária de usuários de drogas para desintoxicação, inclusive, solicitada por qualquer operador SISNAD e inclusão das comunidades terapêuticas como espaços prioritários para o cuidado e com previsão de financiamento público. Em resumo, houve um recrudescimento punitivo do estatuto médico-jurídico que se revela tanto pelo agravamento penal aos considerados traficantes, como por meio da imposição da abstinência e de medidas de exceção aos usuários, a exemplo da internação involuntária.

Esse complexo cenário desafia o Serviço Social, enquanto forma de especialização da divisão social e técnica do trabalho, que tem como matéria de sua intervenção as múltiplas expressões da questão 
social. Nesta sociedade produtora de mercadorias, a qual se estabelece como uma forma própria de relação entre os homens, o Serviço Social conduz-se como elemento integrante da reprodução das relações sociais "atinge a totalidade da vida cotidiana, expressando-se tanto no trabalho, na família, no lazer, na escola, no poder, etc., como também na profissão" (IAMAMOTO; CARVALHO, 1996, p. 72)

Nesse sentido, como profissão que participa das relações sociais de classe - e, portanto, das respostas praticadas pelo Estado à "questão das drogas" -, o Serviço Social brasileiro tem construído suas respostas profissionais do ponto de vista teórico, ético-político e prático-interventivo. Nos últimos trinta anos, vem assumindo o compromisso com a defesa da liberdade, da democracia e dos direitos sociais, sob orientação de um projeto profissional crítico voltado aos interesses dos trabalhadores, na luta pela eliminação do racismo e de outros modos de opressão, contra toda forma de autoritarismo, na defesa da garantia e efetivação dos direitos sociais e humanos.

Embora seja razoável considerar que esta postura assumida pelo conjunto da categoria profissional, expresso nas instâncias organizativas, de formação e de atuação profissional, se apresente, por princípio, como resistência e contraposição à ideologia proibicionista e suas formas de materialização, a incorporação do debate crítico sobre drogas no seio do Serviço Social brasileiro, de modo mais particular, ocorreu tardiamente. Inicialmente, destaca-se no campo da produção teórica, por meio de pesquisas realizadas nas pós-graduações na área. Apenas posteriormente, esta discussão aparece mais decisivamente na agenda política do Conjunto Conselho Federal de Serviço Social/Conselhos Regionais de Serviço Social (CFESS/CRESS) e mediado por um movimento externo à profissão: pelo consenso forjado (BRITES, 2015) de uma suposta epidemia de crack em 2011.

O discurso de uma ameaça à saúde pública por meio de uma epidemia de crack, exigiu do Estado respostas na forma de políticas sociais, implicando na ampliação de espaços ocupacionais que requisitaram o trabalho de assistentes sociais. Algumas destas políticas, foram guiadas por direções punitivistas, higienistas e arbitrárias, divergindo da orientação crítica e ético-política que caracteriza o projeto profissional. No seio desta contradição, de uma política alinhada com a ideologia proibicionista e da necessidade de uma prática de resis- 
tência ao modo moralizador no trato com esta questão, o debate foi amadurecido nos espaços de discussão da categoria. Com isso, o Conjunto CFESS-CRESS ousadamente assumiu a crítica ao proibicionismo, à política de guerra às drogas e se posicionou em defesa da regulamentação do mercado de drogas e dos direitos dos usuários de psicoativos.

O Serviço Social, pois, alcança avanço importantíssimo, destacado nas posições políticas das direções das entidades e nas produções teóricas sobre esta posição. Entretanto, observa-se certo distanciamento de um significativo número de profissionais que estão mais diretamente no campo da atuação, em relação a estas posições. A superação deste distanciamento, no campo do exercício profissional, é um dos grandes desafios a serem enfrentados atualmente pela profissão diante da "questão das drogas". Apresenta-se como uma necessidade a ultrapassagem das práticas balizadas pela perspectiva medicalizadora, moralizante e criminalizadora.

É problemático o tratamento homogeneizador e patologizador daqueles que fazem uso de drogas. Precisa-se, neste sentido, romper com o binômio doença-desvio, assistência-repressão, que indistingue relações diversas para com as substâncias psicoativas, tratando, muitas vezes, uso, abuso e dependência como sinônimos. Trata-se aqui de retirar do campo da moral, da criminologia e da religião, o trato desta questão, entendendo suas contradições e as diversas possibilidades de uso.

De modo particular, a Política sobre Drogas no campo da saúde, apresenta-se a partir de um duplo direcionamento: o ideal da abstinência e a estratégia de redução de danos. $O$ primeiro, se materializa por meio de estratégias de atenção alinhadas à ideologia proibicionista e ao punitivismo moralizador e penal, voltadas ao controle dos comportamentos considerados desviantes. O segundo, parte da compreensão de que aspectos desta questão se manifestam como processos de sofrimento psíquico e que deve ser tratado como tal, a partir de práticas que se destaquem pelo respeito à autonomia e pela afirmação dos direitos sociais e humanos, como uma potente ética do cuidado.

A priorização e a expansão das comunidades terapêuticas como lugar de tratamento e/ou acolhimento para usuários de psicoa- 
tivos deve mobilizar preocupação do sujeito coletivo profissional, pois estes espaços se constituem com base naquele primeiro direcionamento nas políticas de saúde, o da abstinência. Esta é mais uma provocação que se apresenta para a profissão atualmente, já que estes espaços ganham mais visibilidade e apoio financeiro do Estado por meio da Secretaria Nacional de Política Sobre Drogas, como indica a Nova Lei de Drogas. Estas instituições negam a condição de sujeitos de direitos dos usuários de psicoativos, os etiqueta, os estigmatiza e realizam a assistência orientada pelo castigo e a punição, violando a própria dignidade humana e a laicidade do Estado; mas, também, apresentam uma funcionalidade político-econômica de desmonte do Sistema Único da Saúde (SUS) e privatização dos recursos do fundo público.

O relatório de fiscalização produzido pelo CFESS, intitulado, "A inserção de assistentes sociais nas comunidades terapêuticas: considerações sobre o trabalho profissional", identificou a realização de competências e atribuições profissionais completamente divergentes e conflitantes às requisições do projeto ético-político e da regulamentação da profissão. Problemático ainda mais, é o fato de um número significativo destas instituições, tratarem a "questão das drogas" por um viés religioso, considerando o uso como pecado, ou mesmo como possessão demoníaca, tirando-a inclusive do campo da racionalidade científica. Nesta lógica, a atuação das profissionais de Serviço Social desvia-se de suas atribuições por meio de atividades como: aplicação de testes para identificação do nível de dependência; atividades de cunho religioso como aulas, cultos, oração, leitura da Bíblia; grupos de espiritualidade e acompanhamento da laborterapia.

Já no chamado campo sociojurídico, que compreende o espaço de trabalho no Judiciário, na Defensoria Pública, no Ministério Público, nos sistemas prisional, socioeducativo e de segurança pública, têm intrínseca transversalidade com a Lei de Drogas. O passo a ser dado aqui é aproximar assistentes sociais ao horizonte da crítica ao punitivismo, aos processos de transnacionalização do controle social e à gestão penal da classe trabalhadora, afastando-se das implicações do populismo penal e do senso comum punitivo que se impõe ao trabalho dos assistentes sociais. As competências e atribuições profissionais no campo da justiça criminal não devem se submeter às visões 
policialescas e criminalizantes com base no moralismo penal característico destas instituições. As requisições institucionais não podem comprometer o legado da intervenção crítica e competente da profissão e nos transformar em agentes da Lei e da Ordem.

Daí a importância do diálogo estratégico com os campos de saber da criminologia crítica, da teoria crítica da punição, do abolicionismo penal, que possibilitam apreender as contradições do Estado penal e da exceção na realidade brasileira diante das inúmeras ameaças aos direitos humanos e sociais e das conquistas do Estado democrático e de direito. Sobretudo, na compreensão da funcionalidade da economia política da morte mobilizada pela Política de Guerra às Drogas, que se conduz para uma determinada classe e raça, conformando-a em vida matável.

\section{Considerações finais}

O debate sobre punição e dispositivos de controle social, tal como a Lei de Drogas, demonstra profunda relevância na conjuntura mundial e nacional, na medida em que, cada vez mais, um amplo leque de indivíduos está submetido à lógica dos mecanismos de exceção e práticas governamentais pautadas pela lógica totalitária. Uma reflexão crítica nesta área implica afastar-se do senso comum punitivista, muitas vezes, reforçado pelas agências de criminalização midiática e pelos discursos fundados no populismo penal construídos pelos que estão no poder, como forma de produzir certo terror que justifique a ascensão do uso da violência pelo Estado e a tomada de medidas excepcionais que se tornam cada vez mais comuns no cotidiano das democracias modernas.

Reafirmamos que a proibição das drogas, na verdade, é um fracasso exitoso. Conforme Rodrigues (2017), um fracasso na tentativa de eliminar as drogas no mundo; porém, um exitoso dispositivo de produção de desviantes, de controle pelo cárcere, seja nas prisões ou nos manicômios renovados como as comunidades terapêuticas ou, simplesmente, pela eliminação dos dispensáveis nas cotidianas "guerras contra o tráfico". E neste último sentido podemos atestar o êxito do proibicionismo, como poderoso instrumento de criminaliza- 
ção e genocídio das classes e raças indesejáveis, isto é, das juventudes negras periféricas.

O discurso de defesa social, da proteção e segurança dos cidadãos de bem fundamentado na eliminação do inimigo, cuja expressão sintomática é bordão bandido bom, é bandido morto, reatualiza e promove práticas evidentemente neofascistas, racistas, higienistas e eugênicas, tais como o Projeto de Lei para Regulamentação da Posse de Armas, a Lei Anticrime e a Nova Lei de Drogas do governo Bolsonaro.

O incremento dos dispositivos penais na sociedade brasileira, como mediação dos conflitos entre as classes, nos provoca a realizarmos a crítica sobre algo que compõe a história do Serviço Social no país e legitima sua funcionalidade como profissão do controle. Falamos aqui do punitivismo, ainda hoje tão presente e requisitado à profissão. Atualmente, inúmeras assistentes sociais, inseridas nas políticas sociais e criminais sobre drogas, são requisitados a produzir respostas profissionais para a gestão da barbárie.

Medidas penais e extrapenais de controle social reclamam a participação de assistentes sociais na execução da punição e do controle de determinadas práticas e desvios morais atribuídas aos indivíduos etiquetados socialmente. Estereótipos médicos e criminais como de loucos, dependentes químicos ou envolvidos com o crime são distribuídos pelo racismo estrutural nosso de cada dia, em que as pessoas negras quase sempre são os alvos preferenciais. As mudanças regressivas nas políticas de drogas e de saúde mental contribuem para o aprofundamento da necropolítica neoliberal (MBEMBE, 2017).

Com base nestas reflexões, gostaríamos de apontar dois grandes desafios para o Serviço Social brasileiro. O primeiro se refere ao enfrentamento da onda conservadora que se manifestou de modo mais amplo nos últimos anos no Brasil e que ataca as bases éticoteóricas que fundamentam nosso projeto profissional. O conservadorismo como forma de pensamento e experiência prática é resultado de um contra-movimento aos avanços da modernidade e, nesse sentido, suas reações são restauradoras e preservadoras, particularmente, da ordem capitalista e de instituições como o mercado, a família e a igreja que o consolida. $O$ segundo diz respeito aos desafios políticos que se particularizam na sociedade brasileira por meio do último pro- 
cesso que temos vivido. Referimo-nos à violenta necessidade - e essa necessidade que é violenta e sempre se manifesta, também, sob a forma da violência aos proletários - da acumulação capitalista, que tem a classe trabalhadora como, potencialmente, ameaçadora da ordem.

Por fim, este debate ganha materialidade quando articulado com o conjunto das lutas sociais como campo da "questão das drogas", como os movimentos antiproibicionistas e de redução de danos, os movimentos negros, a luta antimanicomial, as frentes pelo desencarceramento, as resistências contra o genocídio da população negra, entre outros, que têm encontrado como resposta do Estado o uso da força e da repressão violenta como forma de neutralizá-los. Para esse enfrentamento, temos que construir possibilidades de ruptura com a lógica produtora da invisibilidade perversa dos jovens ninguéns eliminados cotidianamente nos fronts da insana guerra às drogas como mercadorias sem valor e descartáveis. "Que não têm nome, têm números. Que não aparecem na história universal, aparecem nas páginas policiais da imprensa local. Os ninguéns, que custam menos do que a bala que os mata" (Eduardo Galeano).

\section{Referências}

AGAMBEN, G. Estado de exceção. 2. ed. São Paulo: Boitempo, 2004. AlBUQUerque, C. S.; AZEVEDO, E. NOBRE, M. C. Q. Drogas, "questão social" e políticas sociais: entre os direitos de cidadania e a criminalização da pobreza. In: ALBUQUERQUE, C. S.; GOLÇALVES, A. M. (Org.). Drogas e proteção social: os desafios da intersetorialidade. Fortaleza: Expressão, 2016.

ALBUQUERQUE, C. S.; CARVALHO, T. Conexões entre a questão racial e a questão social na formação social brasileira. In: MEDEIROS, E.; NOGUEIRA, L. BEZERRA, L. (Org.). Formação social e Serviço Social: a realidade brasileira em debate. São Paulo: Outras Expressões, 2019.

ALMEIDA, S. L. Racismo estrutural. São Paulo: Polén Livros, 2019. 
BARATTA, A. Criminologia crítica e crítica do direito penal. Introdução à sociologia do direito Penal. 6. ed. Reimpressão. Rio de janeiro: Revan, 2013.

BARREIRA, C.; MOURA, R.; LINS, A. L. Homicídios aumentam; vítimas ainda são as mesmas In: RAMOS, S. et al Racismo, motor da violência: um ano da Rede de Observatórios da Segurança Rio de Janeiro: Anabela Paiva, Centro de Estudo de Segurança e Cidadania (CESeC), 2020.

BATISTA, V. M. Difíceis ganhos fáceis: drogas e juventude pobre no Rio de Janeiro. Rio de Janeiro: Revan, 2003.

BOITEUX, L. Brasil: Reflexões críticas sobre uma política de drogas repressiva. Revista Sur - Revista Internacional de Direitos Humanos, São Paulo, v.12, n. 21, ago., 2015.

Controle penal sobre as drogas ilícitas: o impacto do proibicionismo no sistema penal e na sociedade. 2006. Tese (Doutorado em Direito) - Faculdade de Direito, Universidade de São Paulo, São Paulo, 2006.

BRITES, C. M. Ética e uso de drogas: uma contribuição da ontologia social para o campo da saúde pública e da redução de danos. 2006. Tese (Doutorado em Serviço Social) - Programa de Estudos PósGraduados em Serviço Social, Pontifícia Universidade Católica de São Paulo, São Paulo, 2006.

. Política de Drogas no Brasil: usos e abusos. In: BOKANY, V. (Org.). Drogas no Brasil: entre a saúde e a justiça: proximidades e opiniões. São Paulo: Editora Fundação Perseu Abramo, 2015

CARNEIRO, H. Drogas: a história do proibicionismo. São Paulo: Autonomia Literária [recurso eletrônico, E-book], 2019.

CASARA, R. R. R. (Org.). O estado pós-democrático: neo-obscurantismo e gestão dos indesejáveis. Rio de Janeiro: Civilização Brasileira, 2017.

CONSELHO FEDERAL DE SERVIÇO SOCIAL - CFESS. Relatório de fiscalização: Serviço Social e a inserção de assistentes sociais nas comunidades terapêuticas no Brasil. Brasília: CFESS, 2018. Disponível em: < 
http://www.cfess.org.br/arquivos/RelatorioCFESS-ComunidadesTerapeuticas2018-Site.pdf>. Acesso em: 14 set. 2020.

FERNANDES, F. A revolução burguesa no Brasil: ensaio de interpretação sociológica. São Paulo: Globo, [1975], 2006. lar, 2017.

. 0 significado do protesto negro. São Paulo: Expressão popuHIRATA, D. V.; GRILLO, C. C.; DIRK, R. Operações policiais e ocorrências criminais: Por um debate público qualificado. Rio de Janeiro: Grupo de Estudos Novos llegalismos (GENI), Universidade Federal Fluminense (UFF), 2020.

IAMAMOTO, M. V; CARVALHO, R. Relações sociais e Serviço Social no Brasil: esboço de uma interpretação histórico-metodológica. 11. edição. São Paulo; Lima: Cortez; CELATS, 1996.

KARAM, M. L. A esquerda punitiva. Revista discursos sediciosos - crime, direito e sociedade. Rio de Janeiro: Relume-Dumará, n. 1, ano 1, p. 79-92, 10 semestre, 1996.

\section{LIMA, R. C. C. Uma história das drogas e do seu proibicionismo}

transnacional: relações Brasil - Estados Unidos e os organismos internacionais. 2009. Tese (Doutorado em Serviço Social) - Escola de Serviço Social, Universidade Federal do Rio de Janeiro. Rio de Janeiro, 2009.

MARX, K. O capital: crítica da economia política. Livro I: o processo de produção do capital. São Paulo: Boitempo, 2013.

MBEMBE, A. Necropolítica. São Paulo: n-1 edições, 2018.

NETTO, J. P. Uma face contemporânea da barbárie. Revista Novos Rumos, Marília, v. 50, n. 1, 2013.

RODRIGUES, T. Drogas e proibição: um empreendedorismo moral. In: FEFFERMANN, M.; FIGUEIREDO, R.; ADORNO, R. (Org.). Drogas \& sociedade contemporânea: perspectivas para além do proibicionismo. São Paulo: Instituto de Saúde, 2017.

RUSCHE, G.; KIRCHHEIMER, O. Punição e estrutura social. 2. ed. Rio de Janeiro: Revan, 2004. 
SANTOS, V. E.; SOARES, C. B. O consumo de substâncias psicoativas na perspectiva da saúde coletiva: uma reflexão sobre valores sociais e fetichismo. Saúde \& Transformação Social. Florianópolis, v. 4, n. 2, p. 38-54, 2013.

VALOIS, L. C. O direito penal da guerra às drogas. Belo Horizonte: Ed. D’Plácido, 2017.

WACQUANT, L. Punir os pobres: A nova gestão da miséria nos Estados Unidos [A onda punitiva]. Rio de Janeiro: Editora Revan, 2007. 